\title{
Analysis of coolant flow at the outlet of the physical model of the fuel assembly II. of the nuclear reactor VVER 440 / V213
}

\author{
Peter Mlynár ${ }^{1}$, František Világi ${ }^{1,{ }^{*},}$ Zdenko Závodný ${ }^{1}$, František Urban ${ }^{1}$ and František \\ Ridzoñ ${ }^{1}$ \\ ${ }^{1}$ Slovak University of Technology in Bratislava, Faculty of Mechanical Engineering, Institute of \\ Energy Machinery, Nám. slobody 17, 81231 Bratislava, Slovakia
}

\begin{abstract}
To safely and efficiently load the fuel assemblies of the VVER 440 / V 213 nuclear reactor, the relation between the temperature of the coolant at the outlet of the fuel assembly, measured by a thermocouple in the assembly's axis, and the mean coolant temperature, present in the plane of the thermocouple, must be analysed. Based on the analysis of the coolant flow at the output of the physical model of the fuel assembly I. [1] and published CFD simulations $[2,3,4]$ it was shown, that a special attention has to be paid to the influence of the water flow in the central tube on the temperature and velocity profile of the coolant at the thermocouple's plane in the fuel assembly. For this reason, an experimental device with a physical model of the fuel assembly II. of the nuclear reactor VVER 440 / V 213 was designed, manufactured, and operated at the Faculty of Mechanical Engineering STU in Bratislava.
\end{abstract}

\section{Introduction}

The fuel and control assemblies used in nuclear reactors are the most important parts of the reactor. The design of the assembly determines the technical and economic properties of the nuclear power plant, e.g. efficiency, fuel cycle, operational safety, reliability, and economy. During the operation of the VVER 440 / V 213 pressurized water reactor, an irregular temperature profile over the radius of the active zone is formed, depending on the type, burnout, and location of individual assemblies. The temperature and velocity distribution over the radius of the fuel rods are also irregular, and this also applies to the coolant exiting from the fuel element. The coolant flows through the alignment grid, where the shape of the cross-sectional area changes from hexagonal to circular so that the flow area at the exit from the fuel assembly also changes. The coolant temperature field equalizes. Additional mixing of the coolant occurs during its flow at the inlet of the protection tube block. The temperature of the coolant at the outlet of the fuel assembly is measured with a thermocouple, located in the axis of the fuel assembly at a distance of about $300 \mathrm{~mm}$ from the end of the fuel rod bundle. For safe and efficient loading of nuclear reactor fuel assemblies, the relation between the coolant outlet temperature measured by the

* Corresponding author: frantisek.vilagi@stuba.sk 
thermocouple and the mean coolant temperature at the thermocouple's plane must be analysed by measurements on the physical models or by validated CFD simulations.

\section{Physical model of fuel assembly II. of nuclear reactor VVER 440 / V 213}

To create a physical model of fuel assembly II. the dimensions from the available construction drawings and documentation of the VVER 440 / V 213 reactor's fuel assembly were used. The simplified model is mainly used to analyse the influence of the water flow through the central tube on the temperature and velocity profile of the water flowing at the outlet of the fuel assembly of the nuclear reactor. The model consists of a circular cut-out of the fuel assembly of the VVER 440 / V 213 nuclear reactor, the casing and the fuel rods are made from stainless steel. In the fuel assembly casing, which has an inner diameter of $\varnothing$ $81.7 \mathrm{~mm}$, there are 30 fuel rods with a diameter of $\varnothing 9.53 \mathrm{~mm}$. There are also three fuel rods of $\varnothing 6 \mathrm{~mm}$, resp. $\varnothing 5 \mathrm{~mm}$ at the casing and a central tube with a diameter $\varnothing 11 \mathrm{~mm}$ (Fig. 1). The heated water flows in the assembly around the fuel rod bundle (Fig. 2). There are 26 fuel rods in the assembly, which are blinded on both sides. With the selected four tubes marked as A, B, C, and D, the cold water is supplied to the model. At the end plane of fuel rods, the heated water is mixed with cold water. In this way, the temperature profile at the outlet of the fuel rods is modelled. The $2770 \mathrm{~mm}$ long fuel rods are held in a vertical position by 11 simplified spacer grids (Fig. 3). The central tube is closed from the bottom. The openings in the central tube serve to hold the spacer grids and at the same time the water flowing through the assembly is sucked in through them (Fig. 4). A holder with a mixing grid is attached to the upper side of the central tube (Fig. 5). The physical model of fuel assembly II. is at the scale of 1.068: 1 compared to the fuel assembly of the VVER 440 / V 213 reactor. The experimental device with a physical model II. of a fuel assembly consists of a pump with a frequency converter, a fuel assembly, a supply line, a discharge line, and a system for adding cold water to the stream of hot water flowing through the fuel assembly model. Hot and cold water is supplied from a public water supply.

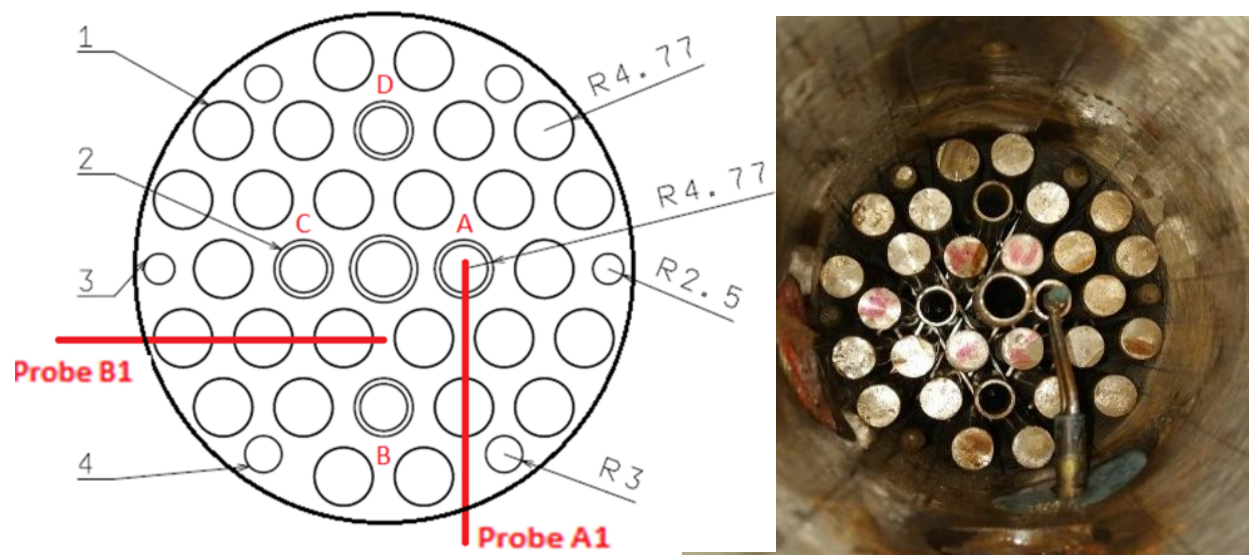

Fig. 1. Fuel rod bundle with central tube and probes A1, B1 located above the end of the fuel rod bundle

1,3 and 4 - fuel rods, 2 - fuel rods A, B, C a D with cold water supply 


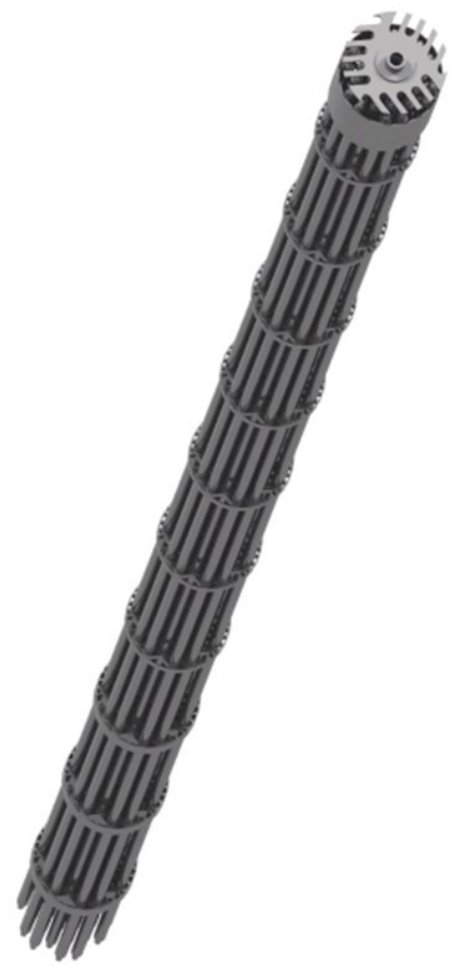

Fig. 2. Experimental device with the physical model of fuel assembly II.

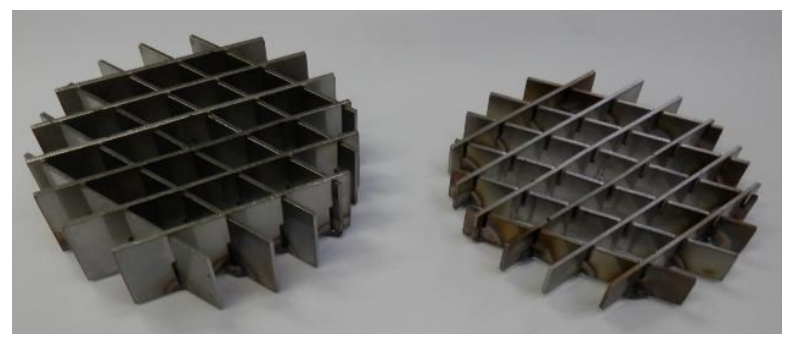

Fig. 3. Simplified spacer grids

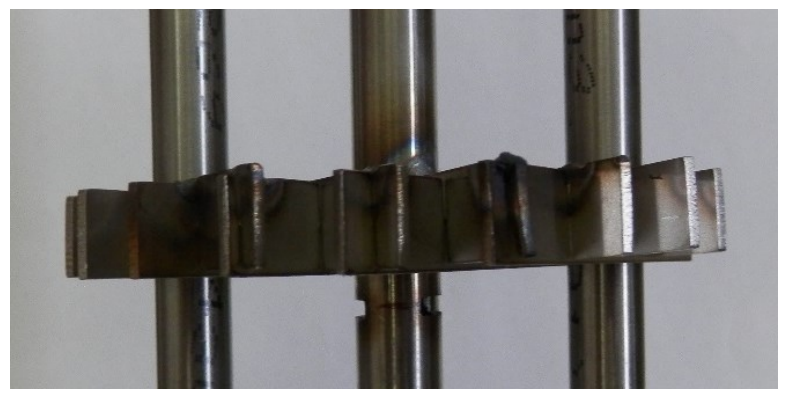

Fig. 4. Part of the central tube with holes and two fuel rods housed in the spacer grid 

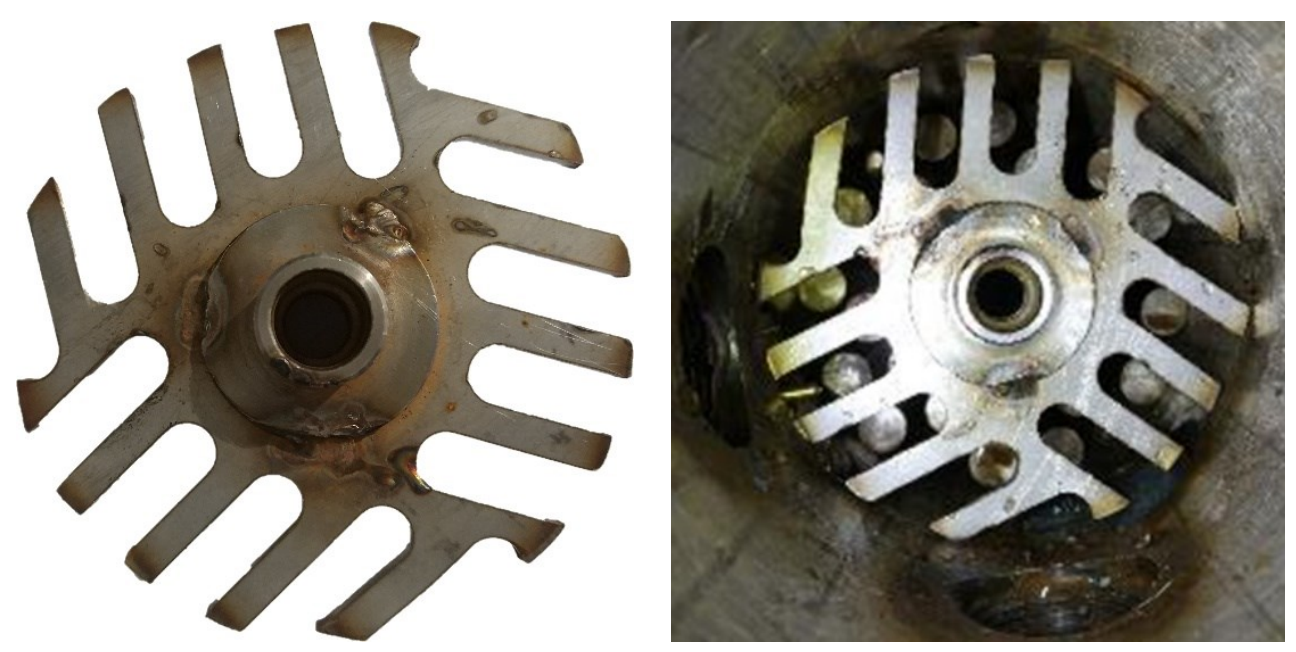

Fig. 5. The alignment grid with the holder

\section{Physical similarity of water flow at the outlet of the fuel assembly of the nuclear reactor VVER 440 / V 213 and physical models of the fuel assemblies I. and II.}

The mass flow of the cooling water through the fuel assembly in the VVER 440 / V 213 reactor is $26.31 \mathrm{~kg} . \mathrm{s}^{-1}$. The flow of the cooling water with a temperature of $300{ }^{\circ} \mathrm{C}$ at the outlet of the fuel assembly in the plane of the thermocouple can be characterized by the Reynolds number Re 4,735.106.

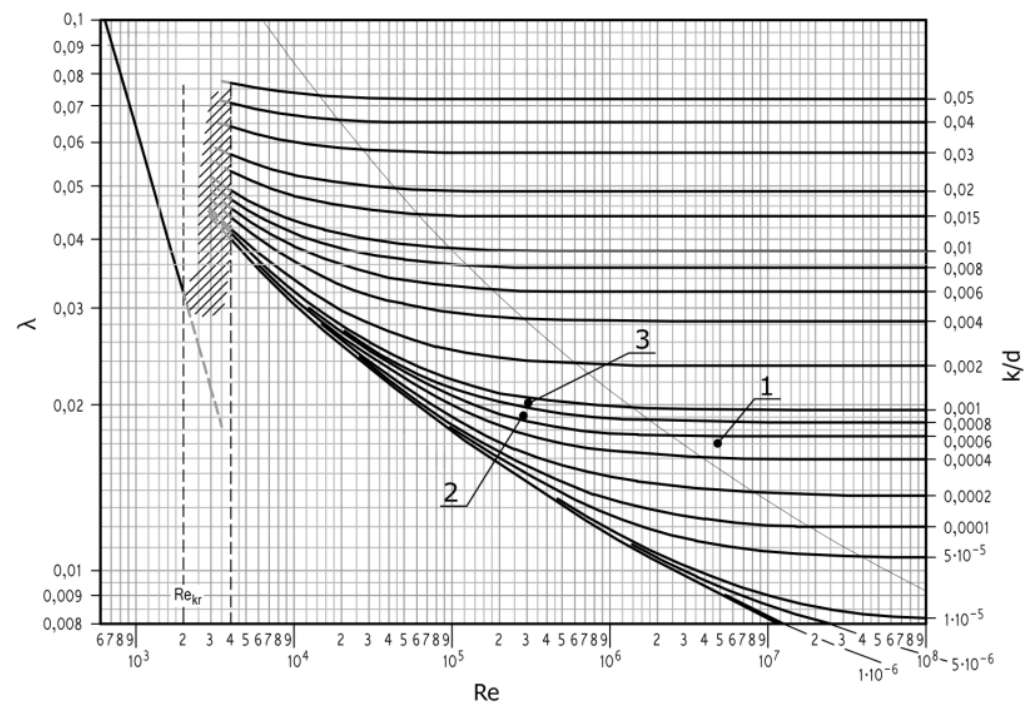

Fig. 6. Coefficient of length losses $\lambda$ in relation to the Reynolds number Re and relative roughness $\mathrm{k} / \mathrm{d}$

1 - fuel assembly of the nuclear reactor VVER 440 / V 213, 2 - the physical model of the fuel assembly I., 3 - the physical model of the fuel assembly II. 
In the physical models I. and II. of the fuel assembly, we are able to work with water temperatures up to $60{ }^{\circ} \mathrm{C}$ due to the method of heating the water in the condensing boiler for the physical model I. and the centrally prepared hot water for the physical model II. High values of the dynamic viscosity $\eta$ of the flowing water in the physical models of fuel assemblies I. and II. reduce the magnitude of the Reynolds number Re to 2,979.10 5 and $3,033.10^{5}$, respectively. Fig. 6 shows a Moody diagram with the values of the length loss coefficient $\lambda$ as a function of the Reynolds number Re, and the relative roughness $\mathrm{k} / \mathrm{d}$ of the fuel assembly of the VVER 440 nuclear reactor (point 1), as well as the physical model of fuel assembly I. (point 2), and the fuel assembly model II. (point 3). The values of the Reynolds number and the length loss coefficient $\lambda$ for a real fuel assembly are in the fully turbulent region (point 1). Velocity and temperature profile measurements in the fuel assembly models I. and II. are performed in the vicinity of the transitional flow regime, wherein the case of water flow, the length loss coefficient $\lambda$ is close to a constant value (points 2 and 3). By maintaining the dimensional and physical similarity between the VVER 440 / V 213 reactor fuel assembly and the physical models of fuel assemblies I., II, the measurement results of the models correspond to the real coolant flow at the outlet from the fuel assembly of the nuclear reactor.

\section{Measurements of temperature and velocity fields of the coolant at the outlet of the fuel assembly physical model II. of the nuclear reactor VVER 440 / V 213}

The main measurements are performed in three planes at the outlet of the fuel assembly physical model II (Fig. 7, Fig. 8).

- $1 \mathrm{st}$ plane is at the front of the alignment grid at distance of $21.5 \mathrm{~mm}$ from the end of the fuel rod bundle. The temperature discontinuity caused by the supply of cold water through selected pipes A, B, C, or D is determined. Probe A1 is traversed directly above the outlet of pipe A and next to pipes B and D. Probe B1 is traversed next to pipes C, B.

- $\quad$ 2nd plane is behind the alignment grid in the constriction of the fuel assembly II, $50.1 \mathrm{~mm}$ from the end of the bundle and $3.5 \mathrm{~mm}$ from the outlet of water from the central tube. The temperature and velocity field of the coolant is measured by combined probes A2 and B2. Probe A2 is traversed above tubes B and D and above the outlet of the central tube. Probe B2 is traversed above tubes $\mathrm{C}$ and $\mathrm{A}$ and above the central tube. The second plane is specific by the reduced water flow towards the central tube, due to the shape of the alignment grid. The water sucked in by the openings of the central tube is discharged from this tube above the alignment grid.

- $\quad 3 \mathrm{rd}$ plane is at the outlet tube at distance of $360 \mathrm{~mm}$ from the end of the fuel rod bundle. In this plane, there is a thermocouple in the real fuel assembly, which measures the temperature of the water at the fuel assembly outlet of the VVER 440/V 213 reactor. The combined probes A3 and B3 were traversed in the same way as the probes in the 2nd plane. A system of pressure transducers connected to Pitot probes is present with resistance thermometers and an orifice plate to measure the water flow through the assembly. 


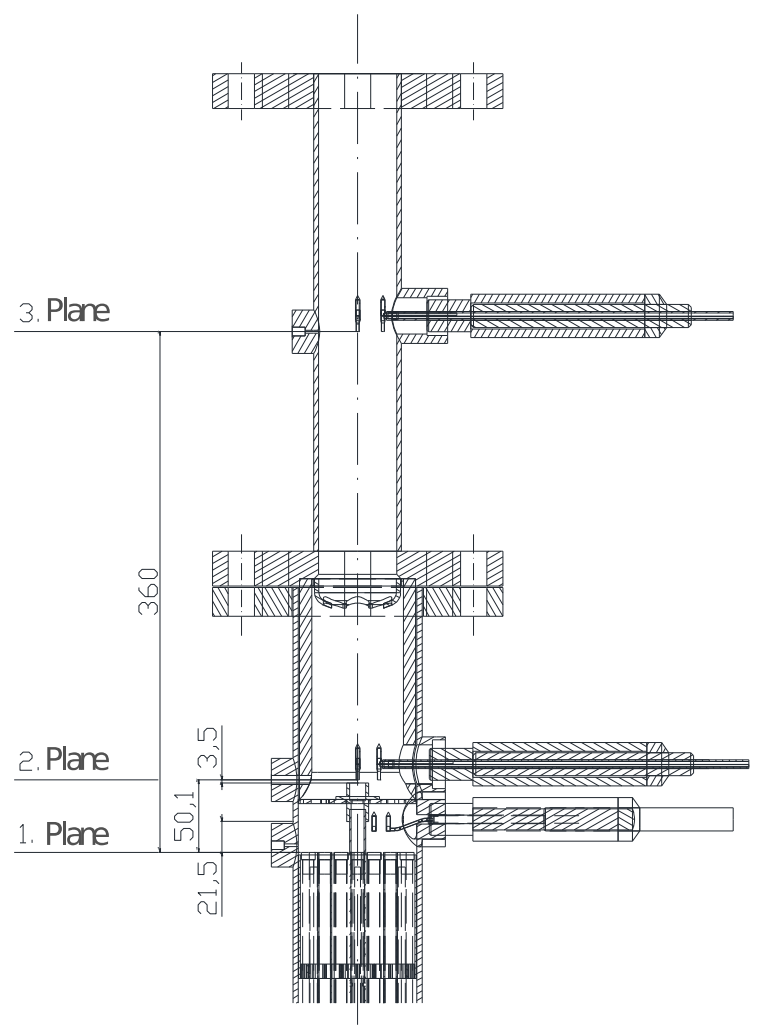

Fig. 7. Section through the outlet of the fuel assembly II.

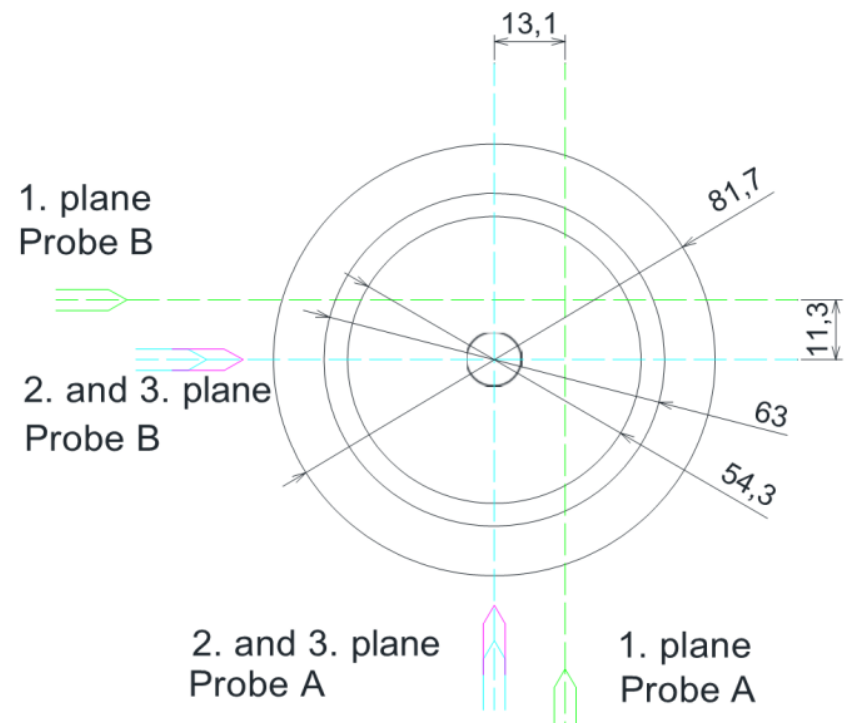

Fig. 8. The mutual position of probes in fuel assembly II. 


\section{Coolant flow at the outlet of the fuel assembly model II. of the nuclear reactor VVER 440 / V 213}

The goal of the measurements was mainly to determine the effect of the temperature discontinuity of the coolant at the outlet of the fuel rod bundle in plane 1 on the water temperatures $t_{\mathrm{A} 3} 0, \mathrm{t}_{\mathrm{B} 3 \_0}$ measured by the combined probes $\mathrm{A} 3$ and $\mathrm{B} 3$ at the axis of the fuel assembly model II. in plane 3 . The water temperatures $t_{A 3 \_} 0, t_{B 3} 0$ are compared with the calculated mean temperature $t_{\text {mean }}$ in plane 3 . A total of 18 measurements [6] were performed, of which 10 measurements without cold water supply and 8 measurements with cold water supply through any combination of pipes A, B, C, or D of the physical model of the fuel assembly II. Measurements are marked according to the format M_XXXX_Y, Y where individual letters mean:

- M - measurement,

- XXXX - 1 to 4 characters, 0 - without cold water supply, with cold water supply via any combination of pipes $\mathrm{A}, \mathrm{B}, \mathrm{C}$ or $\mathrm{D}$,

- Y, Y - mass flow of water through the fuel assembly expressed in $\mathrm{kg} \cdot \mathrm{s}^{-1}$.

\subsection{Analysis of measurements without cold water supply to the physical model of the fuel assembly II.}

During the 10 measurements performed [6], water with a temperature ranging from 28.99 ${ }^{\circ} \mathrm{C}$ to $40.59{ }^{\circ} \mathrm{C}$ and mass flow ranging from $1.89 \mathrm{~kg} . \mathrm{s}^{-1}$ to $4.34 \mathrm{~kg} . \mathrm{s}^{-1}$ flowed through the physical model. Cold water was not supplied through any of the tubes A, B, C, nor D during these measurements. The results of the measurement of the coolant flow rate in the 2nd and 3rd planes without the addition of cold water for variants M_0_1,9 and M_0_4,3 are graphically shown in Figs. 9. Around the central tube, the water flow rate increased rapidly. The maximum velocity was at the axis of the fuel assembly model. The shape of the velocity and temperature distribution profile in the 2 nd plane depends on the shape of the alignment grid and in the case of the cold water supply, on the variant of cold water supply through pipes A, B, C, or D in the plane of the end of the fuel rods. The water flow rate through the whole assembly $\mathrm{m}_{\mathrm{cl}}$ was measured by an orifice. From the measured values of dynamic pressures by probes A3, B3, and the subsequently calculated water flow velocities in the plane 3 , the flow rate $\mathrm{m}_{\text {trav }}$ can be determined. The relative deviation $\left(\mathrm{m}_{\mathrm{cl}}\right.$ $\left.\mathrm{m}_{\text {trav }}\right) / \mathrm{m}_{\mathrm{cl}}$ of the compared values of water flows is in the range of $-3.21 \%$ to $1.94 \%$ for all measurement variants. The values of relative flow deviations indicate the correct measurement of dynamic pressures by probes A3, B3 and the subsequent evaluation of the water flow rate in plane 3 of the physical model of the fuel assembly II. From the measured velocity profiles of water flow in the 3 rd plane, it can be stated that a balanced turbulent velocity field is present in this plane. The mean velocities of water flow through the assembly model in plane 3 were in the range of $0.89 \mathrm{~m} \cdot \mathrm{s}^{-1}$ to $1.91 \mathrm{~m} . \mathrm{s}^{-1}$. In particular, the ratio of the water flow through the central tube and the total flow through the fuel assembly model II was investigated. The water flow rates at the walls of the casing decreased by 21.98 to $24.30 \%$ due to the outflow rate of the water flowing out in the axis of the central tube. The water temperatures $t_{\mathrm{A} 3 \_0}, t_{B_{3} \_0}$ measured by combined probes $\mathrm{A} 3, \mathrm{~B} 3$ at the axis of the fuel assembly model in plane 3 , in which the thermocouple in the real fuel assembly of the VVER 440 / V 213 reactor is located, were compared with the calculated mean temperature $t_{\text {mean }}$ in this plane. For measurements carried out without cold water supply, the equality $\mathrm{t}_{\mathrm{A} 3_{3} 0}=\mathrm{t}_{\mathrm{B} 3_{-} 0}=\mathrm{t}_{\text {mean }}$ can be expected. Temperature profile measurements are demanding and are affected by the uncertainty of the measuring chain. Differences in water temperatures $\mathrm{t}_{\mathrm{A} 3 \_0}, \mathrm{t}_{\mathrm{B} 3}{ }_{0}, \mathrm{t}_{\text {mean }}$ of the order of hundreds of ${ }^{\circ} \mathrm{C}$ (from $-0.03{ }^{\circ} \mathrm{C}$ to $0.06{ }^{\circ} \mathrm{C}$ ) are acceptable. 


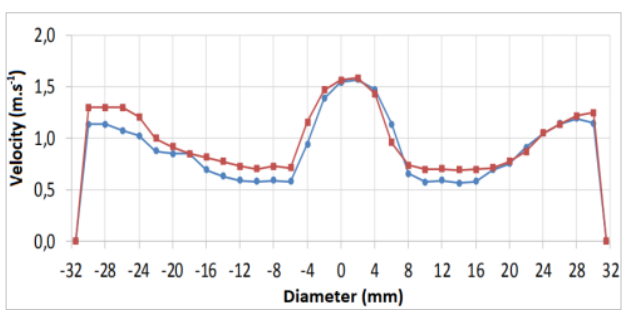

a) Velocity profile in plane $2-$ M_0_1,9

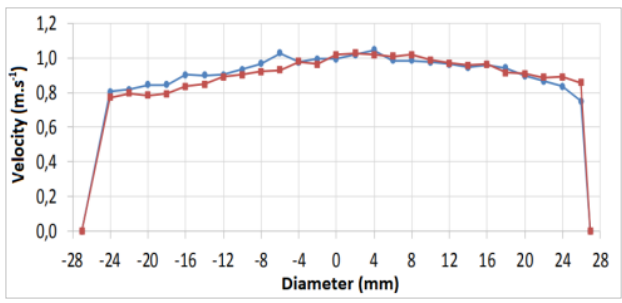

c) Velocity profile in plane 3 - M_0_1,9

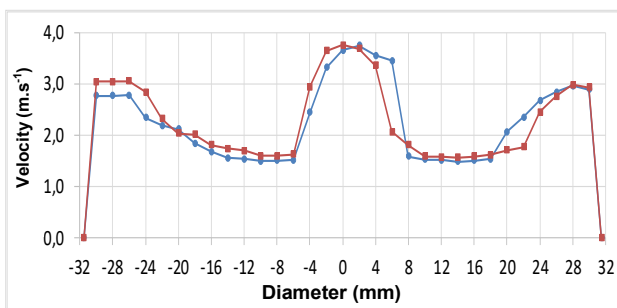

b) Velocity profile in plane 2 - M_0_4,3

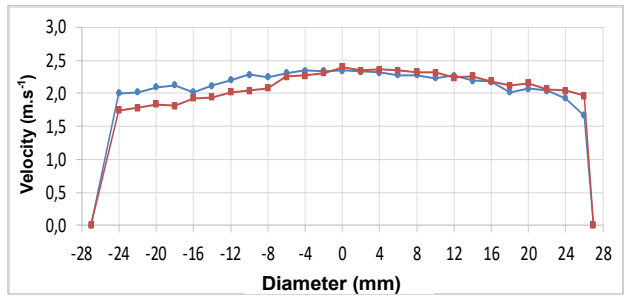

d) Velocity profile in plane 3 - M_0_4,3

$\longrightarrow$ Probe A Probe B

Fig. 9. Measurements $M \_0 \_1,9$ and $M \_0 \_4,3$

\subsection{Analysis of measurements with cold water supply to the physical model of the fuel assembly II.}

A total of 8 measurements [6] were performed with isokinetic cold water supply through different combinations of tubes A, B, C, or D. Water with mass rate from $2.06 \mathrm{~kg} . \mathrm{s}^{-1}$ to 4.27 $\mathrm{kg} . \mathrm{s}^{-1}$ and with a temperature ranging from $38.90{ }^{\circ} \mathrm{C}$ to $39.86{ }^{\circ} \mathrm{C}$ flowed through the fuel assembly model II. The supplied cold water temperatures $t_{\mathrm{vys} A B C D}$ at the outlet of the pipes ranged from $33.21{ }^{\circ} \mathrm{C}$ to $35.13{ }^{\circ} \mathrm{C}$, with a temperature of $15{ }^{\circ} \mathrm{C}$ at $\mathrm{A}, \mathrm{B}, \mathrm{C}, \mathrm{D}$ pipes inlets. When cold water was supplied through all pipes A, B, C, and D (M_ABCD_2,1), the water flow through the assembly had to be reduced to $2.06 \mathrm{~kg} \cdot \mathrm{s}^{-1}$ to maintain the pressure in the system. The goal of the measurements in which the cold water was isokinetically supplied through the tubes A, B, C, or D was to experimentally determine the temperature profiles in planes 2 and 3 depending on the temperature discontinuity created in the 1 st plane of the fuel assembly model II. From the temperature profiles in plane 3, it can be judged to what extent the temperature field has equalized with respect to the temperature profiles in planes 1 and 2, due to the alignment grid, changes in the flow cross-section, and the shape of the rosette in plane 3. Evaluation of measurements by isokinetic addition of cold water through pipe A to the physical model of fuel assembly II. is graphically illustrated in FIG. 10. The measurement variant is marked M_A_4.3, the water flow through the assembly is $4.27 \mathrm{~kg} . \mathrm{s}^{-}$ ${ }^{1}$. The individual measurement variants characterize the temperature differences of the water flowing at the outlet of the fuel assembly II. in planes 1, 2, and 3. The temperature difference $\Delta t_{1}$ is determined as the difference between the maximum and minimum temperature of the water flowing in plane 1 measured by probes $\mathrm{A} 1$ and $\mathrm{B} 1$, as well as temperature differences $\Delta \mathrm{t}_{2}$ in the 2 nd plane measured by probes A2, B2, and $\Delta \mathrm{t}_{3}$ in the $3 \mathrm{rd}$ plane by probes A3, B3. In the 1st plane of the fuel assembly model II. the largest temperature difference was $\Delta t_{1}=6.00{ }^{\circ} \mathrm{C}$ during the measurement M_A_4.3. The temperature differences in the $2 \mathrm{nd}$ and $3 \mathrm{rd}$ plane were $\Delta \mathrm{t}_{2}=1.36{ }^{\circ} \mathrm{C}$ (the lowest temperature difference $\Delta \mathrm{t}_{2}$ ) and $\Delta \mathrm{t}_{3}=0.35{ }^{\circ} \mathrm{C}$ wherein both correspond to the measurement 
M_A_4,3. The lowest temperature difference $\Delta \mathrm{t}_{1}=0.62{ }^{\circ} \mathrm{C}$ was recorded during the measurement M_B_4.3. In the 2nd plane of the fuel assembly II. the largest temperature difference was $\Delta \mathrm{t}_{2}=2.44{ }^{\circ} \mathrm{C}$ during the measurement M_ABCD_2.1. The temperature differences in the $1 \mathrm{st}$ and $3 \mathrm{rd}$ plane were $\Delta \mathrm{t}_{1}=2.37{ }^{\circ} \mathrm{C}$ and $\Delta \mathrm{t}_{3}=0.34{ }^{\circ} \mathrm{C}$ during measurement M_ABCD_2.1. In the 3rd plane of the fuel assembly model II. the largest temperature difference was $\Delta \mathrm{t}_{3}=0.67{ }^{\circ} \mathrm{C}$, during the measurement M_BD_3.0 and temperature differences in the $1 \mathrm{st}$ and 2 nd planes $\Delta \mathrm{t}_{1}=2.93{ }^{\circ} \mathrm{C}$ and $\Delta \mathrm{t}_{2}=2.28{ }^{\circ} \mathrm{C}$, respectively. The lowest temperature difference was $\Delta \mathrm{t}_{3}=0.20{ }^{\circ} \mathrm{C}$ during the measurement M_BD_3.0. Coolant mixing at the outlet of the physical model of the fuel assembly II. indicates the differences between the temperatures $t_{A 3}{ }_{A}, t_{B}{ }_{3} 0$ measured by the probes $A 3$ and B3 in the axis of the assembly model and the calculated mean temperature $t_{\text {mean }}$ of the water flowing in plane 3 . The defined parameters are the coolant temperature as $t_{3 \_} 0=\left(t_{A_{-} \_}\right.$ $\left.+t_{\mathrm{B} 3 \_} 0\right) / 2$, measured in the axis of the assembly model, and the mean temperature difference expressed as $\Delta t=t_{\text {mean }}-t_{3 \_}$. By quantitative result of water mixing at the output of the physical model of the fuel assembly II. the temperature difference $\Delta \mathrm{t}$ in the $3 \mathrm{rd}$ plane was in the range of $-0.015{ }^{\circ} \mathrm{C}$ (M_A_4.3) to $0.055^{\circ} \mathrm{C}$ (M_ABC_2.4). The relation between the coolant temperature in the plane $\overline{3}$, measured in the axis of the fuel assembly model II., and the mean coolant temperature in this plane is found experimentally. Plane 3 is the plane, where the thermocouple intended for measuring the temperature of the coolant at the outlet of the VVER 440 / V 213 reactor fuel assembly is positioned.

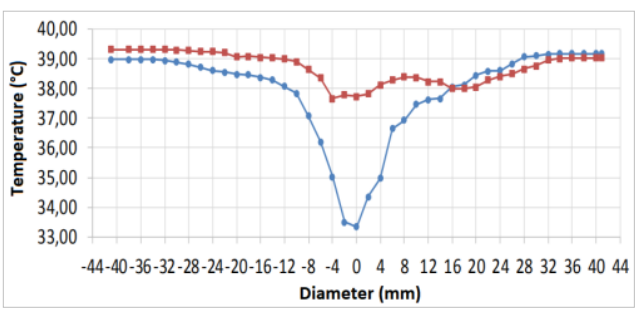

a) Temperature profile in plane 1

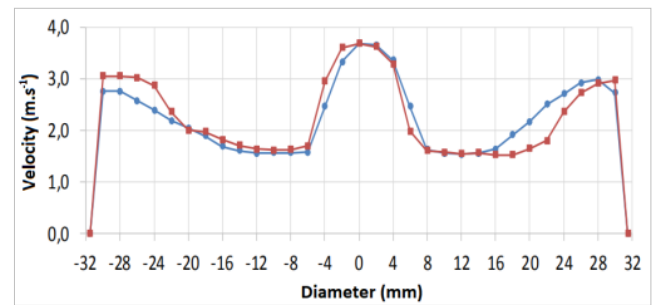

b) Velocity profile in plane 2

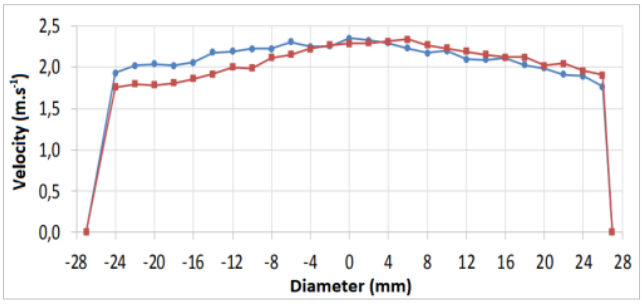

d) Velocity profile in plane 3

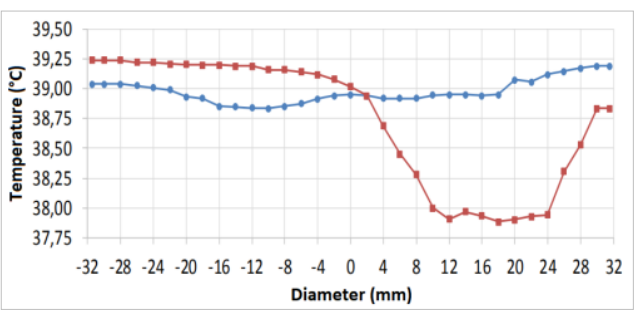

c) Temperature profile in plane 2

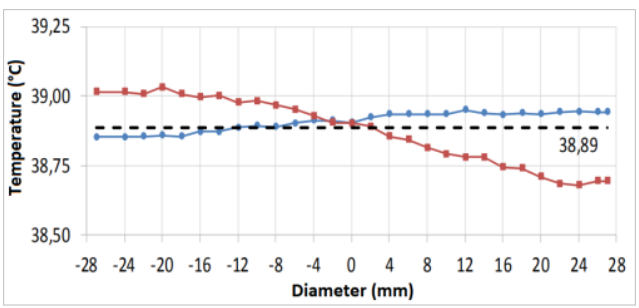

e) Temperature profile in plane 3

$\longrightarrow$ Probe $\mathrm{A} \longrightarrow$ Probe $\mathrm{B}-\mathrm{t}_{\text {mean }}$

Fig. 10. Measurement $M \_A \_4,3$ 


\section{Validation of the CFD model of the coolant flow at the outlet of the fuel assembly physical model II.}

Measured values of temperatures and flow rates of the coolant at the outlet of the fuel assembly model II. variants M_A_4.3, M_B_4.3, M_BC_3.0, M_ABC_2.4, and M_ABCD_2.1 were used for CFD simulations. As the initial boundary conditions for the CFD calculation, the values of temperature and velocity of the coolant flowing in the bundle of fuel rods were used, specifically in tubes A, B, C, and D with cold water supply in plane 1 and a central tube in plane 2. The CFD calculations of variant M_A_4,3 characterized by isokinetic addition of cold water through pipe A shows that the largest temperature differences in planes are $5.26{ }^{\circ} \mathrm{C}$ in the 1 st plane, $1.30{ }^{\circ} \mathrm{C}$ in the 2 nd plane, and $0.13{ }^{\circ} \mathrm{C}$ in the $3 \mathrm{rd}$ plane. The difference between the CFD calculated mean coolant temperature in the $3 \mathrm{rd}$ plane and the temperature measured in the axis of the $3 \mathrm{rd}$ plane is $0.004{ }^{\circ} \mathrm{C}$. Results of CFD simulation of coolant flow at the outlet of the fuel assembly model II. variant M_A_4,3 are in good agreement with experimentally determined values (chapter 5.2). There is a similar agreement when comparing the results of CFD simulations with the measured data of variants M_B_4.3, M_BC_3.0, M_ABC_2.4, and M_ABCD_2.1. For this reason, the CFD model of the coolant flow at the outlet of the physical model of the fuel assembly II can be considered as validated.

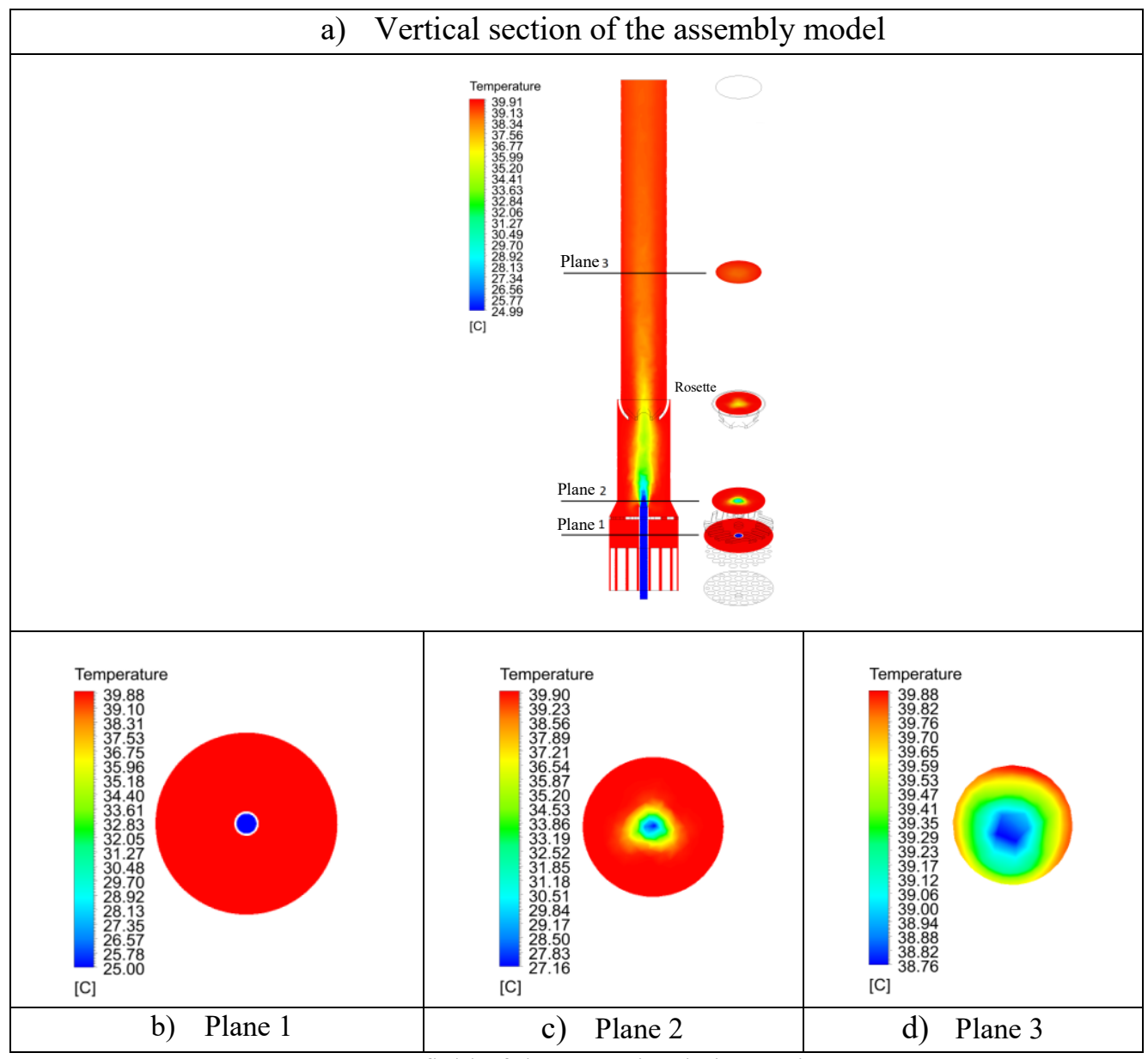

Fig. 11. Temperature field of the CFD simulation variant $S_{-} 0 \_4,3 \_40$ 
The temperature of the hot water flowing through the bundle of fuel rods and the cold water flowing out from the pipes A, B, C, or D is limited by the method of heating the hot water and by the construction of the physical model of the fuel assembly II. The largest difference between these temperatures was $6.0^{\circ} \mathrm{C}$, recorded in the measurement variant M_A_4.3. In the fuel assembly of the VVER 440 / V 213 nuclear reactor, the temperature difference can be up to $15.0{ }^{\circ} \mathrm{C}$ due to the uneven heating of the coolant in the fuel rod bundle and the flow of coolant sucked through the holes in the central tube. As a comparison with the temperature ratios of the coolant in the real fuel assembly, a CFD simulation of the coolant flow was performed at the outlet of the fuel assembly model II. variant S_0_4,3_40. The initial boundary conditions of temperature and velocity of the coolant flowing in the bundle of fuel rods were chosen as $40.0^{\circ} \mathrm{C}$ and $1.50 \mathrm{~m} . \mathrm{s}^{-1}$, respectively. As well as at the outlet of the central tube in the $2 \mathrm{nd}$ plane as $25.0{ }^{\circ} \mathrm{C}$ and $3.60 \mathrm{~m} . \mathrm{s}^{-1}$. The difference between these temperatures was $15.0{ }^{\circ} \mathrm{C}$. In FIG. 11 the temperature field of the CFD simulation S_0_4,3_40 with the supply of water through the central tube is shown. In the 2nd plane, the temperature difference is $15.0^{\circ} \mathrm{C}$. In the $3 \mathrm{rd}$ plane, the water is still not perfectly mixed and we observe a temperature difference of $1.15^{\circ} \mathrm{C}$. The coolant temperature decreases towards the axis of the outlet pipe, where the thermocouple is located in the actual fuel assembly. According to the CFD calculations, the temperature difference between the calculated mean coolant temperature and the temperature in the fuel assembly axis is 0.54 ${ }^{\circ} \mathrm{C}$.

\section{Conclusion}

The coolant temperature at the outlet of the fuel assembly of the VVER 440 / V 213 nuclear reactor is measured by a thermocouple located in the axis of the fuel assembly. It is simply assumed that the coolant is thoroughly mixed at the outlet of the fuel assembly and the temperature measured by the thermocouple is the mean temperature of the coolant. For safe and efficient loading of nuclear reactor fuel assemblies, this assumption must be verified by measurements on physical models or validated CFD simulations to analyse the relationship between the coolant temperature measured by the thermocouple and the mean coolant temperature in the thermocouple location plane. At the Faculty of Mechanical Engineering STU in Bratislava, an experimental device with a physical model of a fuel assembly II. of nuclear reactor VVER 440 / V 213 was designed, manufactured, and operated. The simplified model is mainly used to analyse the effect of water flow through the central tube on the temperature and velocity field of water flowing at the outlet of the nuclear reactor fuel assembly. By respecting the dimensional and physical similarity of the fuel assembly of the VVER 440 / V 213 reactor and the physical model of the fuel assembly II. the results of the measurements on the models are in accordance with the real flow of coolant at the outlet of the real fuel assembly. A total of 18 measurements on the physical model are presented at different flow rates and temperature discontinuities of the coolant. Temperature and velocity profiles in three planes at the outlet of the model were analysed. From the measurements of the velocity profiles of the water flow in plane 3 of the thermocouple location in the fuel assembly, it can be stated that the turbulent velocity field is balanced in this plane. The experimentally determined difference between the temperature in the axis of the model and the mean temperature for individual measurements in the $3 \mathrm{rd}$ plane was in the range of $-0.015^{\circ} \mathrm{C}$ to $0.055^{\circ} \mathrm{C}$. The coolant mixing at the outlet of the physical model of the fuel assembly II. is very intense. A CFD model of coolant flow at the outlet of the physical model of the fuel assembly II. was created. This model was validated based on the measured values of temperatures and velocities. As a comparison with the temperature ratios of the coolant in the real fuel assembly, a CFD simulation of the coolant flow was performed at the outlet of the fuel assembly model II. variant S_0_4,3_40. 
This variant is characterized by initial boundary conditions of temperature and velocity of the coolant flowing in the bundle of fuel rods as $40.0^{\circ} \mathrm{C}$ and $1.50 \mathrm{~m} . \mathrm{s}^{-1}$, and with boundary conditions at the outlet of the central tube in the 2 nd plane of $25.0^{\circ} \mathrm{C}$ and $3.60 \mathrm{~m} . \mathrm{s}^{-1}$. The difference between these temperatures is $15.0{ }^{\circ} \mathrm{C}$. In the $3 \mathrm{rd}$ plane, the water is still not perfectly mixed, and we observe a temperature difference of $1.15^{\circ} \mathrm{C}$. According to the CFD calculations, the temperature difference between the calculated mean coolant temperature and the temperature in the fuel assembly axis is $0.54{ }^{\circ} \mathrm{C}$.
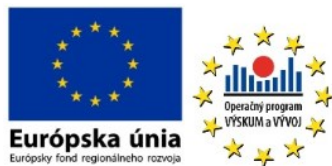

This contribution was created based on the project "Research centre ALLEGRO" (ITMS project code: 26220220198), supported by Operational Programme Research and Development funded by the European Regional Development Fund.

\section{References}

1. F. Urban, L. Kučák, J. Bereznai, Z. Závodný, P. Muškát, Temperature measuring analysis of the nuclear reactor fuel assembly, American Institute of Physics Publising LLC 1608 249-252 (2014)

2. L.L. Kobzar, D.A. Oleksyuk, Experiments on Simulation of Coolant Mixing in Fuel Assembly Head and Core Exit Channel of Assembly Head (AER on VVER Reactor Physics and Reactor Safety, 2006)

3. S. Tóth, A. Aszódi, Detailed Analysis of Coolant Mixing in VVER-440 Fuel Assembly Heads (AER on VVER Reactor Physics and Reactor Safety, 2008)

4. J. Jakubec, V. Kutiš, E. Mojto, Study of mixing grid positioning in fuel assembly of VVER-440, (International Scientific Conference EEE 1 103-106 2014)

5. F. Urban, L. Kučák, J. Bereznai, M. Pulmann, J. Tihányi, Influence of the mixing grid position on the coolant flow at the outflow part of the nuclear reactor fuel assembly physical model and validation of CFD model, Communications 14, 4246 (2012)

6. Z. Závodný, Analysis of coolant flow at the outlet of the physical model of the fuel assembly II. nuclear reactor, Doctoral dissertation thesis, Faculty of mechanical engineering in Bratislava, Bratislava 2018.

7. Z. Závodný, J. Bereznai, F. Urban, Dependency of the Reynolds number on the water flow through the perforated tube. Conference Proceedings Application of Experimental and Numerical Methods in Fluid Mechanics and Energy 2016. Terchová, SR, 27. - 29. 4. 2016. Vol. 1745, (2016).

8. Z. Závodný, J. Bereznai F. Urban, Analysis of the water flow through the simplified central tube of the VVER 440 nuclear reactor fuel assembly. AIP Conference Proceedings. Vol. 1768, (2016) 